\title{
Tobacco Quitline toll-free number on tobacco packets in India: An analysis on outcome
}

\author{
Raj Kumar1,2, Shyam Kanhaiya Saroj², Manoj Kumar² \\ ${ }^{1}$ National Tobacco Quitline Services, Vallabhbhai Patel Chest Institute, University of Delhi; ${ }^{2}$ Department of Pulmonary \\ Medicine, Vallabhbhai Patel Chest Institute, University of Delhi, India
}

\begin{abstract}
On 1 September 2018, 2 year later the launch of National Tobacco Quitline Services (NTQLS), new health warnings on tobacco products packets consisting of NTQLS toll-free number came into effect in India. The present study aimed to measure the effects of printing tobacco Quitline number on tobacco packets on calls to NTQLS. All calls to the NTQLS were monitored over 1 year, six months before and after the tobacco Quitline number on tobacco packets came to effect. Call details such as tobacco user's demographic profile, tobacco use habit, follow-up and
\end{abstract}

Correspondence: Raj Kumar, Director, VP Chest Institute, In-Charge National Tobacco Quitline Services, Vallabhbhai Patel Chest Institute, University of Delhi, 110007 Delhi, India.

Tel. +91.011.27667420/27667102/27667667

E-mail: rajkumarvpci@gmail.com - ncraaivpci@gmail.com

Keywords: Tobacco Quitline; graphical warning; packaging; helpline number; cessation.

Authors' contribution: All the authors played a significant role in conception, design, analysis and interpretation of data, drafting article or revising it critically for important intellectual content. All the authors have read and approved the final version of manuscript and agreed to be accountable for all aspects of the work.

Ethical statement: The article does not contain the participation of any human being and the animal.

Conflict of interest: The Authors have no conflict of interest to declare.

Funding: No grant or forms of financial support availed.

Acknowledgements: The Authors acknowledge the sincere efforts of the National Tobacco Quitline staffs in assisting the data collections of Quitline callers.

Received for publication: 17 September 2020.

Accepted for publication: 22 December 2020.

${ }^{\circ}$ Copyright: the Author(s), 2021

Licensee PAGEPress, Italy

Monaldi Archives for Chest Disease 2021; $91: 1612$

doi: 10.4081/monaldi.2021.1612

This article is distributed under the terms of the Creative Commons Attribution Noncommercial License (by-nc 4.0) which permits any noncommercial use, distribution, and reproduction in any medium, provided the original author(s) and source are credited. quitting status also extracted through Call Detail Record (CDR) files from the server of NTQLS for the purpose of this study. Calls hit on IVR (Interacted Voice Response) increased by 7.7 times, on an average 6064 calls daily hit on NTQLS's IVR after the new health warning consisting of toll-free number on tobacco packets came into effect. Tobacco user registration increased by 3.3 times (18039 vs 5469). Overall, 264.5\% (4790) relative increment in tobacco quitters, as it were only 1314 quitters six months before the new health warning. $100 \%$ callers cited tobacco packets as the primary source of tobacco Quitline toll-free number. The helpline number of Quitline on tobacco packet showed a strong potential to aware the public about the tobacco Quitline. This has increased the number of callers calling to National Tobacco Quitline Services and registrations for tobacco cessation. Sharp increase in calls during the first three months of new health warning and latter diminishing rate of calls is the concern for further study.

\section{Introduction}

Tobacco is the only legal product sold in all the country that can kill half of its users. It is highly accessible, characterized by compulsive drug seeking and abuse and by long-lasting chemical and molecular changes in the brain. The user faces withdrawal symptoms including irritability and anxiety when they want to quit it. The World Health Organization in its global report on trends in prevalence of tobacco use 2000-2025 estimated 1.337 billion current tobacco users in 2018 in the world [1]. There is a common belief that about half a billion people alive today will eventually be killed by tobacco if current tobacco using patterns continue [2]. It is projected on current morbidity and mortality trend that by 2030 , deaths from smoking will be 10 million a year, which means one death in every three seconds [2]. In India, tobacco is used as smokeless and smoked form. $28.6 \%$ (266.8 million) of the population consume tobacco in any form, $10.7 \%$ (99.5 million) smoke, and 21.4\% (199.4 million) use smokeless tobacco (SLT) [3]. Beedis accounted for the largest proportion of smoked tobacco consumed in India, especially among the lower socio-economic group, they consume beedis 8 to 10 times more than cigarette smoking [4]. Khaini and Gutka are the dominant forms of smokeless tobacco (chewable) consumed in India [5]. 38.5\% of current smokers and $33.2 \%$ smokeless tobacco users made a quit attempt in past 12 months. $355.4 \%$ of current smokers and $49.6 \%$ of current smokeless tobacco users were planning or thinking of quitting tobacco use [3].

Preventing tobacco related morbidity and mortality has always been one of the main objectives of public health programs in 
India. In May, 2003, the Government of India has enacted the national tobacco-control legislation namely, "The Cigarettes and other Tobacco Products (Prohibition of Advertisement and Regulation of Trade and Commerce, Production, Supply and Distribution) Act, 2003". [6]. India also ratified the WHOFramework Convention on Tobacco Control (WHO-FCTC) in February2004 [7]. Further, in order to facilitate the effective implementation of the Tobacco Control Law, to bring about greater awareness about the harmful effects of tobacco as well as to fulfill the obligations under the WHO-FCTC, the Ministry of Health and Family Welfare, Government of India launched the National Tobacco Control Programme (NTCP) in 2007- 08 in 42 districts of 21 States/Union Territories of the country [8]. In May 2016, another significant step taken by the Ministry of Health and family welfare, Government of India by introducing Tobacco Quitline namely, "National Tobacco Quitline Services" which help people across the country to access a toll-free number for free telephonic counseling to quit tobacco using habit [9].

In exercise of the power conferred by the Cigarettes and other Tobacco Products (Prohibition of Advertisement and Regulation of Trade and Commerce, Production, Supply and Distribution) Act, 2003 (34 of 2003), the Central Government of India made the rules further to amend the Cigarettes and other Tobacco Products (Packaging and Labelling) Rules, 2008, namely Cigarettes and other Tobacco Products (Packaging and Labelling) Second Amendment Rules, 2018 which came into force from $1^{\text {st }}$ September, 2018.10 With this act every tobacco manufacture bound by the rule to follow the special instructions for packaging all types of smoking and smokeless forms of tobacco products by the word "TOBACCO CAUSES CANCER" and the word "TOBACCO CAUSES PAINFUL DEATH" which shall appear in white font colour on a red background and the words "QUIT TODAY CALL 1800-11-2356" shall appear in white font colour on a black background. The textual health warnings shall be printed with four colors with printing resolution of minimum $300 \mathrm{dpi}$ (dots per inch) $[9,10]$. The aforementioned notification, along with printable versions of the warnings, is also issued in Hindi. The present study aimed to measure the effect of printing tobacco Quitline number on tobacco packets on calls to National Tobacco Quitline Services.

\section{Methods}

The new health warnings are in colour and larger than the previous warnings, for the first time, they feature the Quitline number prominently with effect from $1^{\text {st }}$ September 2018 . The pictorial and textual elements of the health warning together cover $85 \%$ of the front and back panels of the tobacco product packet, with $60 \%$ dedicated to picture and $25 \%$ dedicated to the text. There is one image for the first 12-month rotation period, and another image for the second 12-month rotation period. Any tobacco user who wishes to quit tobacco make call at the designated toll-free number. All calls first hit on the Interacted Voice Response (IVR) system then transferred to the available counsellor followed by the language selection. IVR is an automated phone system technology that allows callers to access information via a voice response system of pre-recorded messages without having to speak to an agent. Registration of tobacco users were done to those active tobacco users who were willing to seek tobacco cessation support from Quitline counsellors. After registration the quit date was set within a week. Minimum of four follow-up (proactive) calls were made to provide tobacco cessation counselling. The first proactive call is made 3-4 days before the set quit date, second proactive call on quit date, third proactive call 3-7 days after the quit date and fourth proactive call 1-3 weeks after the $3^{\text {rd }}$ proactive call date. Quitters were referred to those who abstained tobacco from the date of quit set till the fourth proactive call.

The counsellors at National Tobacco Quitline Services were trained as per the World Health Organization protocol [11]. The counselling included 5 As (Ask, Advise, Assess, Assist and Arrange); 5 Rs (Relevance, Risks, Rewards, Roadblocks, Repetition) in a time period of approximately 15-min counselling session. Subsequently, the telephonic counselling sessions were further increased to moderate ( $\leq 30 \mathrm{~min})$ and intensive counselling (30-40 min) sessions, depending upon the requirement of the tobacco user. For the purpose of this study all calls to the National Tobacco Quitline Services were monitored over 1 year (March 1, 2018 to February 28, 2019), six months before and after the tobacco Quitline number on tobacco packets came to effect. The call details such as tobacco user's demographic profile, tobacco use habit, follow-up and quitting status extracted through Call Detail Record (CDR) files from the server of NTQLS. The data analyses were done through Microsoft Excel 2010 spreadsheet by dividing the study period into two zones. First zone starting from $1^{\text {st }}$ March 2018 to $31^{\text {st }}$ August 2018 i.e. six months before the tobacco Quitline helpline number introduced on all tobacco packets and the second zone starting from $1^{\text {st }}$ September 2018 to $28^{\text {th }}$ February 2019. Relative changes, simple percentages and averages were used as statistical tools for the purpose of this comparative study. By the time, the Quitline was operational six days in a week in two shifts ( 8 a.m. to 2 p.m. and 2 p.m. to 8 p.m.).

\section{Results}

The 12 months data of National Tobacco Quitline Services, six months before and after the print of toll-free number showed a multiple time of increment in number of callers and active registration for tobacco cessation. The demographic profile of month wise calls details was showed in Table 1 .

Before the new health warning consisting of tobacco Quitline number, the numbers of callers were limited to 5469 in six months but after its introduction the caller registration increased to 18039 persons, a massive increment of $229.4 \%$. An average of 116 tobacco users registered daily. This was 34 tobacco users per day during $1^{\text {st }}$ March to $31^{\text {st }}$ August 2019. There was also a huge difference in calls hit on IVR, earlier it was only 123,447 but in second time period zone the calls hit on IVR was 964,049 (680.9\% increase). On an average 6064 calls daily hit on NTQLS's IVR (Figures 1 and 2).

The characteristics of the new callers changed significantly after the introduction of Quitline helpline number on tobacco packets in September 2018. Female participation increased by $345.1 \%$ (227 vs 51). Previously, graduate callers were highest but after the new health warning, the callers educated less than high school ( $10^{\text {th }}$ Standard of education) were leading in enrolling for tobacco cessation. There was also a significant increase in illiterate caller's registration (4.6\% vs 1.9\%). Unmarried caller registration also increased to 9237 as it was recorded 2249 before the Quitline number on packets.

$100 \%$ callers cited the tobacco products packets as the primary source of toll-free number and motivation to initiate a quit attempt. Earlier $42.5 \%$ of the callers cited print media, $22 \%$ from broadcast and social media, $18.4 \%$ reference from known person, $4.1 \%$ ref- 
erence from M-Cessation (short messaging service to quit tobacco) and $13 \%$ got reference from public health seminar, hospitals etc. about the toll-free number.

Overall, 264.5\% (4790) relative increment in tobacco quitters, as it were only 1314 quitters six months before the new health warning.

\section{Discussion}

The Ministry of Health and Family Welfare (MoHFW) first proposed the skull and crossbones in the late 1980s as graphical health warning (GHW) on tobacco products, but it was not implemented due to strong industry opposition [12]. In May 2009, the first graphical health warning (GHW) implemented on bidi, cigarette and smokeless tobacco packets depicting a lung X-ray and an image of diseased lungs for bidi and cigarette packets, and a scorpion for smokeless tobacco packets in Indian union and its territories [12]. Later on several amendments were made for GHW for its size and its content [12]. In April 2016, mandatory display of new health warnings covering $85 \%$ of the principal display area on all tobacco products implemented all over India [13]. These provisions meet Article 11 of the WHO Framework Convention on Tobacco Control (FCTC) packaging and labelling of tobacco products and align with the FCTC Article 11 guidelines with respect to warning size, location, and rotation. According to Global Adult Tobacco Survey (GATS 2016-2017), the $85 \%$ pictorial warnings on all bidis, cigarettes and chewing tobacco packages manufactured and sold in India have resulted in $92 \%$ of adults believing that smoking caused serious illness and $96 \%$ saying use of smokeless tobacco causes serious illness [3]. These discussions showed that GHWs played the important and integral part of tobacco control program in India. Review of literatures suggest that introduction of Quitline telephone numbers on cigarette packets has led to higher call volumes to Quitlines [14-19]. European Smoking Cessation Helplines Evaluation Research (ESCHER) cited the relative increase of $115 \%, 232 \%$, $111 \%$ and $200 \%$ Quitline call volumes for the countries Denmark, France, Ireland and Poland respectively after the Quitline number introduced on GHWs [20]. Canadian Quitline found a relative increase of $160 \%$ in the average monthly call volume during the 7 months after the introduction of the new labels consisting Canadian Quitline telephone number [19]. An

Table 1. Demographic profile of caller 6 months before and after the Tobacco Quitline Help Number on Tobacco packets.

\begin{tabular}{|c|c|c|}
\hline Variables & $\begin{array}{l}\text { Six months before (March to August 2018) } \\
\text { Number of callers } \\
(\mathrm{n}=5469)\end{array}$ & $\begin{array}{l}\text { Six months after (September } 2018 \text { to February 2019) } \\
\qquad(\mathrm{n}=18039)\end{array}$ \\
\hline $\begin{array}{l}\text { Gender } \\
\text { Male } \\
\text { Female }\end{array}$ & $\begin{array}{c}5418(99.07 \%) \\
51(0.93 \%)\end{array}$ & $\begin{array}{c}17812(98.74 \%) \\
227(1.26 \%)\end{array}$ \\
\hline $\begin{array}{l}\text { Age (years) } \\
<14 \text { years (childhood) } \\
15-24 \text { (youth) } \\
25-64 \text { (adults) } \\
65 \text { \& above (seniors) }\end{array}$ & $\begin{array}{c}12(0.22 \%) \\
1592(29.11 \%) \\
3738(68.35 \%) \\
127(2.32 \%)\end{array}$ & $\begin{array}{l}73(0.40 \%) \\
8536(47.32 \%) \\
9313(51.63 \%) \\
117(0.65 \%)\end{array}$ \\
\hline $\begin{array}{l}\text { Marital status } \\
\text { Married } \\
\text { Unmarried } \\
\text { Widowed } \\
\text { Divorced }\end{array}$ & $\begin{array}{c}3200(58.51 \%) \\
2249(41.12 \%) \\
8(0.15 \%) \\
12(0.22 \%)\end{array}$ & $\begin{array}{l}8789(48.72 \%) \\
9237(51.21 \%) \\
8(0.04 \%) \\
5(0.03 \%)\end{array}$ \\
\hline $\begin{array}{l}\text { Education } \\
1^{\text {st }} 10 \\
11^{\text {th }}-12^{\text {th }} \\
\text { Diploma } \\
\text { Graduation } \\
\text { Post-graduation } \\
\text { Professional } \\
\text { Illiterate } \\
\end{array}$ & $\begin{array}{c}1589(29.05 \%) \\
1276(23.33 \%) \\
112(2.05 \%) \\
1831(33.48 \%) \\
368(6.73 \%) \\
191(3.49 \%) \\
102(1.87 \%)\end{array}$ & $\begin{array}{c}6124(33.95 \%) \\
4635(25.69 \%) \\
548(3.04 \%) \\
4697(26.04 \%) \\
993(5.50 \%) \\
216(1.20 \%) \\
826(4.58 \%)\end{array}$ \\
\hline $\begin{array}{l}\text { Occupation } \\
\text { Private sector } \\
\text { Self employed } \\
\text { Government sector } \\
\text { Student } \\
\text { Unemployed } \\
\text { Retired }\end{array}$ & $\begin{array}{c}1442(26.37 \%) \\
2107(38.53 \%) \\
305(5.58 \%) \\
1115(20.39 \%) \\
378(6.91 \%) \\
122(2.23 \%)\end{array}$ & $\begin{array}{c}4579(25.38 \%) \\
8107(44.94 \%) \\
506(2.81 \%) \\
3955(21.92 \%) \\
802(4.45 \%) \\
90(0.50 \%)\end{array}$ \\
\hline $\begin{array}{l}\text { Tobacco use } \\
\text { Smoking } \\
\text { Smokeless } \\
\text { Both (smoking and Smokeless) }\end{array}$ & $\begin{array}{c}2077(37.98 \%) \\
2796(51.12 \%) \\
596(10.90 \%)\end{array}$ & $\begin{array}{l}2995(62.53 \%) \\
12754(70.70 \%) \\
2290(47.81 \%)\end{array}$ \\
\hline Quitters & $1314(24.03 \%)$ & $4790(26.55 \%)$ \\
\hline
\end{tabular}


identical pattern was also observed in Korean Quitline after the inclusion of the Quitline number on cigarette packs [21]. New Zealand tobacco Quitline also found hike in caller registration by $61 \%{ }^{16}$ In our this study the relative increment of $229.4 \%$ in caller's registration at Quitline for tobacco cessation is the good indication that people in India notice the health warning on tobacco packets. It may be also be the reason that the awareness of tobacco Quitline number could not reach to the tobacco users through previous channels. Government of India launched its tobacco Quitline (NTQLS) in 2016, during the initial phase; word of mouth, print, broadcast and social media were playing the main role on creating the awareness of tobacco Quitline helpline number. After the introduction of toll-free number on GHWs, $100 \%$ callers cited the tobacco product packets as the primary source of the Quitline number and motivation to initiate a quit attempt. During these six months (1.09.2018 to 28.02.2019), calls hit on the IVR was also increased manifold (6064 calls per day) creating heavy data traffic on server which led to server failure several times. Increase numbers of calls also pressurized counsellors with heavy workload and busy schedule. Maintaining the quality and breadth of tobacco treatment services by telephone counselling during such exponential rises in Quitline calls was the biggest challenge in front of NTQLS counsellors.

Introduction of new GHW in September 2018 also led to significant changes in caller's characteristics. Number of female callers increased, which showed that the graphical warnings along with tobacco Quitline number significantly increase the number of calls to Quitline. There is also the fact that female in rural portion of India also given less chances to watch television and other media in comparison to males. This may be the reason of less awareness of tobacco Quitline helpline number awareness and lesser female callers before GHW. Prior to insertion of NTQLS helpline number, the number of graduate and higher educated callers were higher due to the reason that prior to this the awareness of tobacco Quitline was done largely through educational programs, seminars in colleges, public lectures and social media which generally not accessible to school student. Number of illiterate callers also increased with $709.8 \%$ relative increase. The study also found that the awareness of Quitline number among illiterate callers was done by their close known educated person who had persuaded them to make call to Quitline. Our other previous studies revealed that the registration of married callers were always in higher proportion than unmarried caller due to the fact that the spouse insist to quit tobacco or married people have higher responsibilities so have more concerns to quit for good health and for their children [22-24]. But in the second time period zone the number of unmarried callers sharply rose by $10.1 \%$, a relative increment of $311.1 \%$ beating the percentage of married callers. The number of married callers on pre- and postGHW were 3,200 (58.5\%) and $8789(48.7 \%)$ whereas unmarried callers were $2249(41.1 \%)$ and 9,237 (51.2\%) respectively. This disapproves our belief that married people are more concern about health and want to quit tobacco than unmarried callers. However there were many challenges during the six-month post GHW due to heavy incoming calls, findings to this study suggest that the counsellors were able to maintain the quality and quantity of telephone counselling to the callers, achieved $26.5 \%$ quit rates on four follow up. There was a sort of "burst" effect at the beginning of the period (September to November) when calls seem rocket to the sky. This effect tends to diminish sensibly over time and this downward trend seems to continue until February is a concern for further study (Figure 2).

\section{Conclusions}

The printing of toll-free number of tobacco Quitline on tobacco packets showed a massive effect. A great number of tobacco users far greater than before, call on the printed helpline for tobacco cessation support". The helpline number of Quitline on packet showed a strong potential to aware the public about the tobacco Quitline, cutting a large amount of expenditure on advertising in TV and print media. This has increased the number of callers calling to National Tobacco Quitline Services and registrations for tobacco cessation. The Quitlines should be prepare in advance to handle the calls burden on per workstation/counsellor, data traffic on server and other technical failures which may arise due to heavy call volumes in initial months of GHWs introduction with Quitline numbers. Further, other researches are required to assess that this increase in call volumes and caller's registration is long lasting or decline due to the hypotheses that people tend to become accustomed to the graphical messages on tobacco packets and do no longer perceive them properly after a certain period.

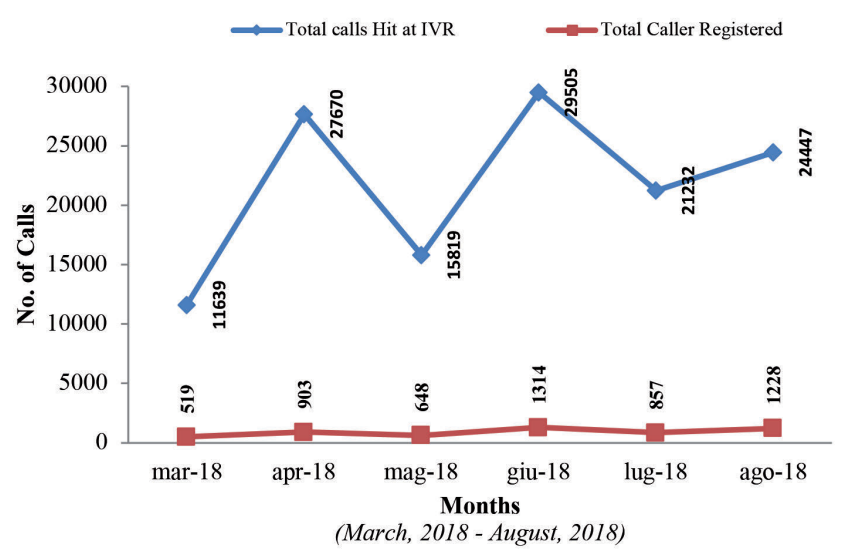

Figure 1. Six months before caller and call hit at Interacted Voice Response (IVR).

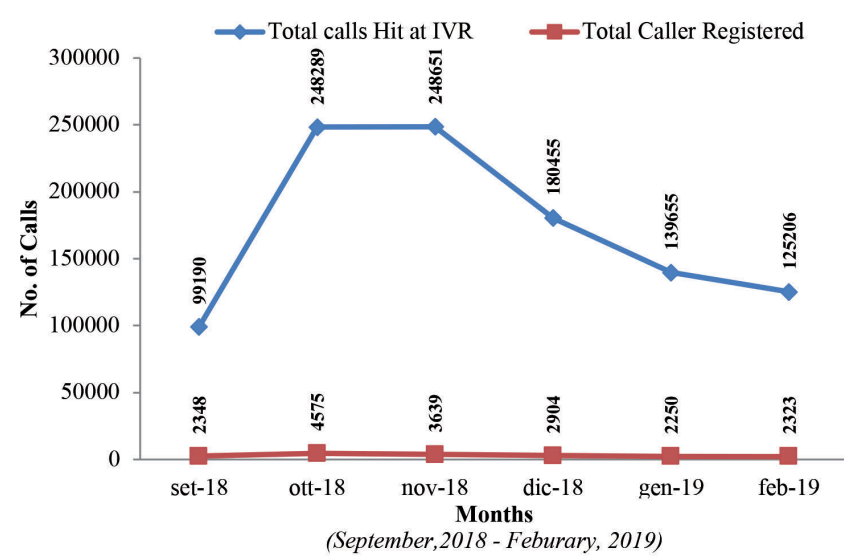

Figure 2. Six months after caller and call hit at Interacted Voice Response (IVR). 


\section{References}

1. World Health Organiszation. WHO launches new report on global tobacco use trends. Accessed: 24 May 24 2020. Available from: https://www.who.int/news-room/detail/19-12-2019-wholaunches-new-report-on-global-tobacco-use-trends

2. World Health Organization. Submission by the Federation of European Cancer Societies to the Public Hearings on the WHO Framework Convention on Tobacco Control. Accessed: 24 May 2020. Available from: https://www.who.int/tobacco/framework/public hearings/F0880086.pdf

3. Global Adult Tobacco Survey. GATS India Report 2016-2017. Mumbai: Tata Institute of Social Sciences (TISS) and New Delhi: Ministry of Health and Family Welfare, 2016.

4. Mohan P, Lando HA, Panneer S. Assessment of tobacco consumption and control in India. Indian J Clin Med 2018;9:1-8.

5. Thakur JS, Paika R. Determinants of smokeless tobacco use in India. Indian J Med Res 2018;148:41.

6. Ministry of law and Justice, Government of India. The Cigarettes and Other Tobacco Products (Prohibition of Advertisement and Regulation of Trade and Commerce, Production, Supply and Distribution) Act, 2003. Accessed: 24 May 2020. Available from: https://legislative.gov.in/actsofparliamentfromtheyear/cigarettes-and-other-tobacco-products-prohibition-advertisement-and

7. National Health Mission, Government of India. WHO Framework Convention on Tobacco Control (WHO FCTC). Accessed: 24 May 2020. Available from: https://nhm.gov.in/ index 1 .php?lang $=1 \&$ level $=\% 203 \&$ sublinkid $=1126 \&$ lid $=636$

8. National Health Mission, Government of India. National Tobacco Control Programme (NTCP). Accessed: 24 May 2020. Available from: https://nhm.gov.in/index1.php?lang=1\&level= 2\&sublinkid $=1052 \&$ lid $=607$

9. Kumar R, Saroj SK. National Tobacco Quit-line Services. Indian J Chest Dis Allied Sci 2016;58:221-3.

10. Press Information Bureau, Government of India. New Specified Health Warning on Tobacco Products packs. Accessed: 26 May 2020. Available from: https://pib.gov.in/PressReleseDetail. aspx?PRID=1640749

11. World Health Organization. Training for tobacco quit line counsellors: telephone counselling. 2014. Available from: https://apps.who.int/iris/handle/10665/113145

12. Sankaran S, Hiilamo H, Glantz, SA. Implementation of graphic health warning labels on tobacco products in India: the interplay between the cigarette and the bidi industries. Tob Control 2015;24:547-55.

13. National Health Mission, Government of India. COTPA 2003 and Rules made thereunder. Accessed: 6 August 2020. Available from: https://nhm.gov.in/index4.php?lang=1\&level=0\&linkid $=459 \&$ lid $=692$

14. Miller CL, Hill DJ, Quester PG, et al. Impact on the Australian Quitline of new graphic cigarette pack warnings including the Quitline number. Tob Control 2009;18:235-7.

15. Wilson N, Li J, Hoek J, et al. Long-term benefit of increasing the prominence of a Quitline number on cigarette packaging: 3 years of Quitline call data. NZ Med J 2010;123:109-11.

16. Wilson N, Weerasekera D, Hoek J, et al. Increased smoker recognition of a national quitline number following introduction of improved pack warnings: ITC Project New Zealand. Nicotine Tob Res 2010;12:72-7.

17. Willemsen MC, Simons C, Zeeman G. Impact of the new EU health warnings on the Dutch quit line. Tob Control 2002;11:381-2.

18. Li J, Grigg M. New Zealand: new graphic warnings encourage registrations with the quitline. Tob Control 2009;18:72.

19. Baskerville NB, Brown KS, Nguyen NC, et al. Impact of Canadian tobacco packaging policy on use of a toll-free quitsmoking line: an interrupted time-series analysis. CMAJ Open 2016;4:E59-65.

20. Bot M, Van der Meer R, Willemsen M. Impact of telephone numbers on cigarette packets on call volumes to quitlines. Den Haag: ESCHER European Smoking Cessation Helplines Evaluation Research; 2007.

21. Park J, Minh LN, Shin SH, Oh J, et al. Influence of new tobacco control policies and campaigns on Quitline call volume in Korea. Tob Induc Dis 2019;17:21.

22. Kumar R, Jha AK, Munish VG, et al. National Tobacco Quitline - A Comparative Study of Prevalence of Smoking and Smokeless Tobacco Use in India: A Brief One-year Report. Indian J Chest Dis Allied Sci 2018;60:221-5.

23. Kumar R, Jha AK, Munish VG, et al. National Tobacco Quitline: The preliminary Indian experience. Indian J Chest Dis Allied Sci 2018;60:7-12.

24. Kumar R, Saroj SK, Kumar M, Mahakud GC. Demographic profile, smoking cessation interventions and continuous abstinence of tobacco users at two years. Indian J Chest Dis Allied Sci 2019;61:31-7. 